\title{
IMPROVING PUBLIC TRANSPORT SERVICE QUALITY THROUGH SUSTAINABLE URBAN MOBILITY PLANNING
}

\author{
MACIEJ MICHNEJ, ${ }^{1}$ TOMASZ ZWOLIŃSKI ${ }^{2}$
}

${ }^{1}$ Cracow University of Technology, Institute of Rail Vehicles, POLAND

e-mail: maciej.michnej@mech.pk.edu.pl

${ }^{2}$ Municipality of Kraków, Department of R\&D Project's, POLAND

e-mail: Tomasz.Zwolinski@um.krakow.pl

RECEIVED
ACCEPTED
JEL
CLASSIFICATION

KEYWORDS

ABSTRACT
9 August 2017

15 December 2017

R41, R42, R52, R58

transport service, mobility, participation, cooperation

This paper presents selected aspects of improving public transport service quality through Sustainable Urban Mobility Planning (SUMP). SUMP is a new concept of transport planning developed and promoted by the European Commission. In contrast to the traditional approach, this concept relies heavily on the involvement of citizens and stakeholders and institutional cooperation. It involves various levels of government and management between neighboring municipalities. The aim of the paper is to provide an overview of the importance of participation and institutional cooperation of SUMP process for the Kraków City.

\section{Introduction}

Located in southern Poland, Kraków is the second largest city in the country with around 760,000 inhabitants. It offers unique historical, cultural and scientific character. In recent decades city's development was based on economic and tourism fields. Kraków welcomes around 8 million tourists each year. Jagiellonian University, with around 150,000 students, is one of the oldest universities in Central and Eastern Europe. Kraków is also known 
for very well developed public transport system, based on tram network. There are 132 bus lines and 24 tram lines serving ca. 1 million passengers every day. The quality of rolling stock and infrastructure has been improved constantly, including offering electronic ticketing solutions, real time information systems for passengers and demand responsive bus transport for example.

In 2016 city of Kraków developed and introduced another update of Transport Policy, as a major step towards implementation of SUMP cycle in the city through participating in the international project CH4LLENGE Addressing the four Key Challenges of Sustainable Urban Mobility Planning, whose goal is to develop innovative, proven in practical action and possible to implement solutions for the four key challenges in sustainable urban mobility planning (Challenge Project, 2014):

1. Stakeholder participation and citizen involvement.

2. Institutional cooperation between sectors and disciplines.

3. Identification of the most effective policy measures.

4. Monitoring and evaluation of progress in SUMP development.

For each above-mentioned challenges, the cities analyse their local mobility situation, develop new strategies and are testing different solutions aiming to overcome barriers in 4 main challenges of Sustainable Urban Mobility Planning. More than forty pilot schemes have been developed and introduced, which provide real results and new lessons learned in the whole transport planning process (Hrelja, Monios, Rye, Isaksson, Scholten, 2017).

\section{Objectives and base conditions for SUMP n the city of Kraków}

Currently, Kraków has not established SUMP document. There are many sectorial documents, and for local transport there are mainly: transport policy (2007, updated 2016), parking programme (2012) and so called Transport Plan (2013) - which deals mainly with the development of public transport in the city and region. All these documents will serve as a basis for future SUMP development. The time horizon of the SUMP will be the year 2030. Updated transport policy is a basic vison-establishing document for the SUMP purposes. There are three main objectives for the city in terms of transport system development:

- to ensure the efficiency of the transport system of the city as sustainable in economic, environmental and social terms,

- further strengthening the role and improvements in the quality of public transport,

- creation of the integrated metropolitan transport system, providing accessibility in the framework of the region, the country and Europe.

Congestion in Kraków has significantly risen in the past decades. High traffic volumes are observed particularly in the city centre. It has been observed that rush hours prolong now up to four to five hours in mornings and afternoons which is a considerable rise in peak hours when traffic is at its highest.

The increased motorisation rate is considered as one of the most important causes of congestion problems. Kraków 's motorisation rate (total number of vehicles/1,000 residents) is comparably high in the European context with 644 vehicles/1,000 residents in 2012. 
Table 1. SUMP objectives for Kraków

\begin{tabular}{ll}
\hline \multicolumn{1}{c}{ Objective } & \multicolumn{1}{c}{ Description } \\
\hline Efficiency & $\begin{array}{l}\text { Maximising the benefits which users can gain from the transport system, after taking into account the costs } \\
\text { of provision and operation of the system. }\end{array}$ \\
\hline Liveable streets & $\begin{array}{l}\text { Pleasant street and outdoor conditions in residential areas. It includes the positive external effects on social, cultural } \\
\text { and recreational activity in neighborhoods, freedom of movement on foot and bicycle, and the reduced sense of danger } \\
\text { for these modes. It is linked to, but separate from, the environmental and safety objectives. }\end{array}$ \\
\hline Environment & $\begin{array}{l}\text { The environmental impacts concerning transport include noise, air pollution, vibration, visual intrusion, severance, } \\
\text { fear and intimidation, and the loss of flora and fauna, ancient monuments and historic buildings through } \\
\text { the consumption of land. The environmental protection objective involves reducing the impact of transport facilities, } \\
\text { and their use, on the environment of both users and non-users. }\end{array}$ \\
\hline Equity and social inclusion & $\begin{array}{l}\text { Equality, especially between different groups in society, in opportunities to travel, costs of travel and environmental } \\
\text { and safety impacts of travel. }\end{array}$ \\
\hline Safety & $\begin{array}{l}\text { Minimising the number of all types of road traffic accidents. Usually expressed through total traffic accident costs } \\
\text { or by accident risk per vehicle kilometre.. }\end{array}$ \\
\hline Economic growth & $\begin{array}{l}\text { The increase in the market value of the goods and services produced by an economy over time. } \\
\text { Finance }\end{array}$ \\
\hline $\begin{array}{l}\text { The procurement (to get, obtain) of funds and effective (properly planned) utilisation of funds. It also deals with profits } \\
\text { that adequately compensate for the cost and risks borne by the transport. }\end{array}$ \\
\hline
\end{tabular}

Source: SUMP Guidelines (2009).

Public transport is less affected by traffic congestion showing a better flow of vehicles and only minor delays. The City of Kraków has already taken several actions to tackle problems related to congestion. A number of demand management measures have been introduced such as the introduction of parking restrictions (fee-based) and access restrictions separating the city in zones $A, B, C$; entering zones $A$ and $B$ is only allowed for inhabitants and for delivery vehicles during certain time windows. The creation of new links between districts by building new ring roads also aims to ease congestion. However, road infrastructure development might be seen contradictory to sustainable mobility and might stimulate rather than reduce car-use.

Parking standards are set in local development plans but only about a third of the city's area is covered by such local plans; implementing parking requirements in the remaining areas is not regulated in a uniform way.

Kraków is one of the most polluted cities in Europe and does not meet European or national air quality standards. It was reported that air quality standards are exceeded on about 200 days a year. A 2012 study, for example, showed that the PM2.5 (PM - particulate matter; fine particles that have diameter of 2.5 micrometers or less) and PM10 (coarse particles fraction in addition to the PM2.5 fraction) levels were exceeded at all measuring points in Kraków. Also the average NO2 (nitrogen dioxide) emissions measured at a station on the second ring road were $80 \%$ above the standard allowed.

\section{Public participation}

The rules and procedures for public participation is governed by Resolution of City Council. According to the above mentioned resolution, the goal of public consultations in the Municipality of Kraków is to create a social participation in matters that are important for the city, such as the draft multi-annual urban development programs and investments, municipal investments and other projects included in the budget and cause a significant change in the living conditions residents by:

- informing the local community about planned by the Municipality of Kraków investment and urban projects, 
- information about the effects of the investments and urban projects,

- promotion solutions for investment and urban projects, their importance for the development of the city and outcomes for residents,

- monitoring public opinion,

- getting to know residents opinions on matters covered by consultations,

- identify proposed solutions and ideas related to these investments and urban projects

- creation of offers of compensation for residents in areas so as to:

- create a plane participation and involvement of citizens,

- develop co-responsibility of citizens for the development of the city.

- obtain the favor of residents for the investment and urban projects.

Public participation carried out by the Municipality of Kraków are divided depending on the scope of the instruments used for:

1. Full participation - they can be carried out using all available instruments of social dialogue (eg. contacts, appointments with the residents of the area covered by the public consultation, mobility forum), promotion and advertising (media campaigns and outside media - eg. leaflets, publications, direct mail) and public relations, that is selected according to the current state of knowledge and practice in this field.

2. Limited participation - information - can be carried out by:

- online platform - a special website with a forum,

- interactive media,

- publications in the local press,

- inserts in the local press,

- information materials distributed in the form of direct mail (traditional or electronic mail)

- own publications of Municipality of Kraków.

Activities related to the conduct of public participation in municipal planning of investments and projects, including activities related to land use planning are carried out by Municipality of Kraków - Division of Communication. Employees of the division are responsible for preparing the Preliminary Municipal Investment Catalogue (PMIC). The catalogue contains a description of the investments planned to be implemented in Kraków in the coming years, it is being developed, among others, based on the resolutions of the City Council and the documents related to investment planning and financial center. Based on the results of the consultation (investments with the most negative perception) in conjunction with the importance of the investment for the development of the City and the type and degree of impact of the investment into an area, the Steering Committee made qualifications of selected investments to the Catalogue of Municipal Investments. The Committee is also responsible for updating the catalogue.

\section{Institutional cooperation}

In Kraków internal and external institutional cooperation partners have been involved in the planning process from the beginning. Local cooperation partners have been involved as active members of the "working groups" appointed by the City mayor. The working groups comprise:

- Chairman - Director of the Department/Office or the Executing Unit or his Deputy,

- a program or project manager,

- authors of the studies, 
- authors of the opinions,

- a representative of the Department of Planning and Investment Monitoring,

- Head of Division,

- a representative of the implementing entity (for investments in the programming phase).

At the meetings the authors present their solutions, while the authors of the opinions and other participants in the meeting send their observations and recommendations. Accepting the recommendations of the studies is done by consensus or decision of Chairman. Contentious issues relevant to policy and/or finance the Municipality defined by the team decides Chairman or Director Division. In relation to particular matters Mayor of Kraków, on the basis of relevant documents (information, justification, the draft resolution), which prepares the appropriate Division, Bureau or Unit.

In 2013 the Mayor of Kraków appointed working group to update the Kraków Development Strategy. The working group, was established with the division on the field of management - an area the impact of local government units in which public services are carried out objectively of a similar nature. During the work on updating the strategy there were created four strategic areas:

- strategic area A - Kraków - a social city,

- strategic area B - Kraków - a modern center of the economy,

- strategic area C - Kraków place of residence and recreation,

- strategic area D - Kraków metropolitan city.

The working groups have been also attended by representatives of social, scientific and economic. Working documents have been placed on dedicated information platforms such as KI AGH - Confluence, Trello, Google Drive. In addition, important documents placed in the Bulletin of the Public Information Office of the City of Kraków.

\section{Monitoring and evaluation}

Currently there are no legal obligations to monitor and evaluate progress in implementing hard and soft measures such as in case of SUMP. However, the situation has changed after funding of projects by the EU started. The fact, that the EU institutions control and monitor the use of fund in each project, among other through evaluating product indicators and strategic results, has been noticed as a good practice.

It has already had a significant impact on planning and management of projects and actions from other sources. There are examples of practices concerning regular monitoring and benchmarking of different transport modes, i.e. surveys among citizens and data collection concerning use of public transport, traffic counting and modelling, etc. There are indicators of products and results proposed for many areas of local transport (i.e. parking, cycling, road system, walking, public transport, traffic safety etc).

City of Kraków has applied „The conformity assessment procedure of actions undertaken by the Municipality of Kraków with accordance to Transport Policy for the Kraków for 2007-2015", which will be likely continued for new transport policy and SUMP processes:

\section{Scope of assessment}

In accordance with the provisions of the Transport Policy for the City of Kraków for 2007-2015, evaluation is taken on the following subjects:

- spatial planning,

- public transport, 
- road system,

- parking,

- cycling,

- organization and management,

- financial and economic policy,

- environmental protection,

- travel behaviour, communication with citizens and community education.

\section{The stages of evaluation}

1. Stage I (evaluation of individual instruments):

For each of the above mentioned issues, for the assessment of the effects of implementation of the provisions transport policy there is the expert method, evaluating the total degree of implementation of the policy in the given area. There are three degrees of the implementation of specific policy instruments with assessments:

1 - low,

2 - average,

3 - high.

2. Stage II (evaluation issues):

In the second stage of evaluation it is determined cumulative value of the indicator evaluation of the implementation of the given issue. This is implemented by calculating the ratio of actual evaluation of the maximum possible value in percent.

3. Stage III (evaluation of policy implementation):

In the third stage of the evaluation it is determined cumulative value of the indicator evaluation of the implementation transport policy. This is implemented by calculating the ratio of actual sum of all issues ratings to sum up the possible ratings expressed in percent. Therefore, it has been proposed the following interpretation of the cumulative rate of evaluating transport policy:

- $0-30 \%$ - the transport policy is not implemented,

- $31-50 \%$ - risk of implementing transport policy,

- $51-70 \%$ - transport policy is implemented well enough,

- $>71 \%$ - transport policy is properly carried out.

Table 2. Summary of the issues that are being assessed

\begin{tabular}{clc}
\hline No. & \multicolumn{1}{c}{ Area } & The maximum sum of ratings \\
\hline 1. & Spatial planning & 24 \\
2. & Public transport & 45 \\
3. & Development of the road system and traffic organization & 36 \\
4. & Parking & 30 \\
5. & Bicycle paths and equipment for persons with disabilities & 24 \\
6. & Organization and management & 12 \\
7. & Economic, financial and fiscal policy & 15 \\
8. & Environmental protection and quality of life & 15 \\
9. & Monitoring of transport behavior and communicating with residents and social education & 21 \\
\hline
\end{tabular}

Source: own data. 
Within the CH4LLENGE project City of Kraków has developed „Monitoring and Evaluation Plan” for future SUMP development.

It is not yet developed and decided how the monitoring and evaluation institutional framework will look like. Basing on the current practices, it will be mainly 2 city units: Roads and PT Authority (ZIKIT) and Department of Urban Utilities (GK), who will be responsible bodies for data collection and all the actions connected with monitoring and evaluation. The data and analysis will be used by the Deputy Mayor responsible for transport system and the City Council.

For the SUMP purposes, it is planned to mainly use the periodical large scale evaluation for overall strategies that are reviewing success at less frequent periods ( 1 to 5 years depending on measures) for which data collection, e.g. household surveys will be carried out. However, basing on the current practices, it will be continued to use all the available tools (i.e. computer modelling, surveys on the PT satisfaction, punctuality, etc. and data concerning volumes on the intersections and from the regulated parking zones) to enable monitoring and evaluation on the short-term basis as well (i.e. half- yearly reports).

It is not yet developed and decided how the stakeholder involvement in evaluation and monitoring will look like. The engagement of stakeholders continues to be relevant for monitoring and evaluation stages for the following reasons:

The stakeholders who set the vision and the prioritized results to realize that vision during the planning stage have the best ideas on how the results would continue to remain relevant to them. They must therefore be involved in identifying the information or feedback that is needed during implementation, which determines the parameters for monitoring and evaluation.

Main databases and tools used in Kraków:

- Visum and Visim modelling software,

- ISDP system (City's Spatial Information System) - including current use of space, local spatial development plans, PT networks, heating, water networks, environmental issues, photo-maps, etc. - in total ca. 700 layers,

- results of different surveys, including user satisfaction surveys, measurements of PT usage, etc.,

- vehicle flows automatic measurements at ca. 40 intersections,

- visual data from cameras at intersections,

- rotation and number of parked cars in the paid parking zone,

- number of bikes used in bike sharing system.

The following table summarises the core outcome indicators as applied for Kraków.

Table 3. The core outcome indicators applied for Kraków

\begin{tabular}{|c|c|c|c|c|}
\hline Objective & Core Indicators & Evaluation & Monitoring & Target \\
\hline 1 & 2 & 3 & 4 & 5 \\
\hline \multirow{2}{*}{ Efficiency } & Average time lost per person $\mathrm{km} /$ ton $\mathrm{km}$ by mode & & $\mathrm{x}$ & \multirow{2}{*}{$\begin{array}{l}\text { Reduction, potentially } \\
\text { based on previous trends } \\
\text { or benchmarking }\end{array}$} \\
\hline & Public transport punctuality & & $x$ & \\
\hline \multirow[t]{2}{*}{ Liveable Streets } & Share of traffic calmed areas & $\mathrm{x}$ & $x$ & \multirow{2}{*}{$\begin{array}{l}\text { Increase, potentially } \\
\text { benchmarking }\end{array}$} \\
\hline & Perceived attractiveness of street environment & $x$ & & \\
\hline
\end{tabular}




\begin{tabular}{|c|c|c|c|c|}
\hline 1 & 2 & 3 & 4 & 5 \\
\hline \multirow[t]{2}{*}{ Environment } & $\mathrm{CO}_{2}$ emissions of traffic in city & $x$ & $\mathrm{x}$ & Decrease \\
\hline & Days exceeding critical levels & $x$ & $x$ & $\begin{array}{l}\text { Decrease, based on EU air } \\
\text { quality standards }\end{array}$ \\
\hline \multirow[t]{2}{*}{ Equity \& Social Inclusion } & Non-car accessibility to main services & $x$ & $\mathrm{x}$ & Increase \\
\hline & Accessibility for disabled people & $x$ & & Increase \\
\hline \multirow[t]{2}{*}{ Safety } & Killed and seriously injured persons & $x$ & $\mathrm{x}$ & Decrease \\
\hline & Accidents by mode & $x$ & $x$ & Decrease \\
\hline \multirow[t]{2}{*}{ Economic Growth } & GDP per capita & $x$ & $\mathrm{x}$ & Increase, potentially based \\
\hline & Employment & $x$ & & $\begin{array}{l}\text { on previous trends or national } \\
\text { targets }\end{array}$ \\
\hline \multirow[t]{2}{*}{ Finance } & Cost recovery for transport investments & $x$ & & Increase \\
\hline & Cost recovery for transport operations & $x$ & & $\begin{array}{l}\text { Increase, potentially based } \\
\text { on previous trends }\end{array}$ \\
\hline
\end{tabular}

Source: own elaboration based on Challenge Project (2014).

Having set the vision, priority results and initial parameters for monitoring and evaluation, the key stakeholders are best placed to ensure that the programmatic initiatives planned would deliver what was intended and the way it was intended.

\section{Summary}

Kraków was the first city in Poland to adopt a sustainable transport policy already in 1993 and has implemented a series of programmes and measures that referred to the use of space and the availability for different transport modes: pedestrian zones and zones with limited access for cars have been introduced and the infrastructure and public transport fleets have been modernised. The city's transport policy, updated in 2016, aims to create an efficient, safe, economical and environmentally friendly transport system for passengers and goods.

Although formal process of SUMP development has not yet started, a new transport policy include and take into consideration SUMP principles. Basing on the current experiences and analysis of different planning processes and documents like (SUMP Guidelines, 2009; Van Wee, Ettema, 2016, pp. 240-248; Banister, 2008; Sivakumar, 2007), generally major issues like public participation, cooperation, measure selection and monitoring and evaluation are properly addressed within transport planning processes. However, in many areas they need improvement or extension.

Like other cities, City of Kraków took part in the testing phase of the European "SUMP Self-Assessment Scheme" and got a score of $65 / 100$ points. This means that planning process is in compliance with several aspects of the SUMP concept. However it does not comply with all basic criteria of the European Commission's SUMP concept and guidelines as presented in the Urban Mobility Package.

\section{References}

Banister, D. (2008). The sustainable mobility paradigm. Transp. Policy, 15, 73-80.

Hrelja, R., Monios, J., Rye, T., Isaksson, K., Scholten, C. (2017). The interplay of formal andinformal institutions between local and regional authorities when creating well-functioning public transport systems. International Journal of Sustainable Transportation, 11 (8), 611-622. DOI: 10.1080/15568318.2017.1292374. 
SUMP Guidelines (2009). Developing and Implementing a Sustainable Urban Mobility Plan. Rupprecht Consult - Forschung und Beratung GmbH Contract ELTISPLUS, no. EACI/IEE/2009/05/S12.558822. Retrieved from: www.mobilityplans.eu.

Van Wee, B., Ettema, D. (2016). Travel behaviour and health: A conceptual model and research agenda. J. Transp. Health, 3, $240-248$. Sivakumar, A. (2007). Modelling transport: A Synthesis of Transport Modelling Methodologies. London, UK: Imperial College London. Challenge Project (2014). Annex 1 - Descritption of Work, Addressing Key Challenges of Sustainable Urban Mobility.

Cite this article aS: Michnej, M., Zwoliński, T. (2018). Improving public transport service quality through Sustainable Urban Mobility Planning. European Journal of Service Management, 1 (25), 179-187. DOI: 10.18276/ejsm.2018.25-22. 